\title{
Sustainable Development Goal 16: Focus on public institutions, World Public Sector Report 2019
}

UNITED NATIONS,

Division for Public Institutions and Digital Government,

Department of Economic and Social Affairs, New York, 2019, pp. 219

Book review by DAGMAR RADIN*

https://doi.org/10.3326/pse.43.4.8

\footnotetext{
* Received: October 2, 2019

Accepted: October 8, 2019
}

Dagmar RADIN, associate professor

Faculty of Political Science, University of Zagreb, Lepušićeva 6, 10000 Zagreb

e-mail: Dagmar.radin@fpzg.hr

ORCiD: 0000-0002-8636-9516 
The Sustainable Development Goals (SDGs), part of the United Nations' 2030 Agenda for Sustainable Development, have by now become a widely recognized and agreed upon set of developmental goals the world community is striving to achieve. One of the goals connected to the success and achievement of all the others is SDG 16, which focuses on public institutions. The World Public Sector Report (WPSR) reviewed here focuses on the part of SDG 16 addressing institutional principles of effectiveness, transparency, accountability, anti-corruption, inclusiveness of decision-making processes, access to information and non-discrimination. More specifically, the Report analyzes the institutional principle of anti-corruption and the cross-cutting issue of gender equality, as well as the public budget process, and risk management in public administration as instruments and tools that can advance the attainment of the SDG16 goal.

The SDGs have become a substantive part of the dialogue in the international organizations focused on developmental issues as well as within national governments, the international academic community and civil society worldwide. While the UN 2030 Agenda is a comprehensive document outlining the priorities, commitments, goals, targets of achieving sustainable development, the SDGs represent seventeen goals identified as action arenas, interconnected with one another, and requiring a comprehensive approach to achieve, through the consideration and inclusion of what are known as "the 5 Ps" (people, planet, prosperity, peace and partnership). If there is one message that the UN sends through the Agenda it is that the only way to achieve all SDGs by 2030 is by considering how actions to achieve one goal affect all the others. While the achievement of all of the SDGs by every country by 2030 is an ambitious, and some would even say unrealistic, target, the goals represent not only specific areas where action is needed to achieve a sustainable world, but also constitute a new understanding and acknowledgment that different segments of development are no longer seen as operating in individual silos, exclusive to the agencies and policy areas targeting them. Rather, the adoption of the SDGs represents an acknowledgment that the SDGs are closely interrelated, dependent on and influencing one another, and that cooperation between the different areas is crucial for their joint success.

One of the SDGs connected to the success and achievement of all the others is SDG 16 which focuses on public institutions. In addition to being a standalone issue, both the Agenda and the SDGs feature institutions as a cross-cutting issue tying in multiple goals. SDG 16 is about promoting "peaceful and inclusive societies for sustainable development, provide access to justice for all and build[ing] effective, accountable and inclusive institutions at all levels".

In light of the importance of SDG 16, the United Nations Department of Economic and Social Affairs (UNDESA) was tasked to inform the review on the progress on the goal for the High-level Political Forum that took place in July 2019 and which gave the opportunity to Member States to discuss this issue. The end product of this undertaking is the WPSR reviewed here. The seventy-four 
individuals contributing to the Report come from a variety of backgrounds and experiences: several UN agencies, international organizations, national governments, public institutions, and academia from across the world, all reflected in the diversity of examples that enrich the Report, as well as the rigor, breadth and depth of knowledge presented in it.

The Report focuses on the part of SDG 16 addressing institutional principles of effectiveness, transparency, accountability, anti-corruption, inclusiveness of decision-making processes, access to information and non-discrimination. However, because of the breadth of the principles, which would make the task of creating a comprehensive Report on all institutional principles and across all issues impossible to complete within a reasonable time frame, the authors have chosen to focus on a sample of issues and instruments that do a reasonably good job of illustrating the state of affairs on the goal attainment and that are tied closely together (ex. Anti-corruption and budgetary processes).

With respect to the level of analysis, the focus of the Report is on national institutions and international only to the extent that they affect the national context, and this is reflected in the varying lengths of the international aspects section in the chapters. This is a sensible approach because the reality of the attainment of SDGs makes the national political arena, where policies are formulated and implemented, even when they are guided or conditioned by international organizations, the most relevant one. While the focus is on institutions, the scope of the Report is further limited to only public institutions, while acknowledging the influence of the private institutions separately and in cooperation through various public-private partnerships. Finally, given the complexity of the topic, which reaches all sectors of socio economic and political development, the Report focuses only on a small sample of issues. The SDG areas included as examples are anti-corruption, and institutions for gender equality, while examples of the tools and instruments include the budget and planning processes, and risk management in public administration. The inclusion of SDG 5, the promotion of gender equality and empowerment of women through public institutions, is especially worth noting as it represents a central issue in the Agenda that is integral to achieving all SDGs.

The structure of the Report and the interconnectedness of the units within it make this Report very much in line with the UN Sustainable Development Agenda, which points to and reinforces the main messages of the Agenda and the SDGs: the interconnectedness and interdependence of all SDGs, both in the areas they cover and in the instruments and tools used to address them. The Report begins with the Executive Summary giving a clear overview of the main points of the Report, that is, focusing on the main aspects of each institutional principle and chapter. What makes the function of the various sections of the Report easier to follow is the actual structure of the chapters, which are divided into three types: the first type looking at one institutional principle of anti-corruption (chapter 2), the second type providing examples of instruments/tools that can also be used to 
achieve other SDGs (chapters 3 and 4), and the third type where through the lens of SDG 16 institutional principles the promotion of gender equality through public institutions is analyzed (chapter 5).

Chapter 1 presents the progress made so far globally on the institutional dimensions of SDG 16. It discusses some issues faced with the very definition of progress, how the authors chose to define it and what challenges exist when attempting to measure it in the context of institutional dimensions. Among other aspects, the chapter presents international dimensions of attempts to measure progress, as well as several interesting examples of issues that may not be easy to see such as: political sensitivity to governance indicators, examples of stakeholder analysis in Chile, and the global review of the participation of environmental impact assessments. The chapter concludes with an assessment of implementation challenges and gaps and leads into the following chapter. Corruption and SDGs are the focus of the second chapter. Given the covert nature of corrupt activities, there are challenges in covering the topic of corruption and, subsequently, anti-corruption strategies but the Report does an excellent job at synthesizing both the theoretical foundations as well as data availability on corruption as well as taking a comprehensive and global analysis of available and documented anti-corruption strategies. As in every chapter, it adds to the understanding of the topic by introducing examples such as corruption in the health care sector in Croatia, as well as examples of social accountability initiatives across the globe, among others. Chapter 3 takes a look at an implementation instrument, the process of public budgeting and does a very thorough job of analyzing a topic that can be tedious and not as easily engaging for stakeholders. However, given the importance of public budgeting as a tool for planning and executing public policies and programs affecting entire populations, the Report adds significant value in explaining how the different institutional principles can be included in the process and how it is related to anticorruption efforts, as well as in offering visual presentations of tools of public engagement in the process, among others.

Chapter 4 addresses risk management in public administration in the SDG context. This topic is particularly challenging given that risk is used in different fields and disciplines differently, and this chapter is able to explain well the different meanings of risk and how it is used in public administration. Furthermore, its importance is highlighted by the fact that risk management, while often mentioned in some fields (such as emergency response management, etc.) is still largely not understood in many areas of public administration as it relates to the public interest rather than private interest, and how it can be used to achieve the SDGs. In addition to the main structure, the chapter offers a variety of examples, such as Liberia's lead managing agencies and alternates for specific risks, providing an overview of the different areas where risk management is needed. Also addressed are such issues as Canada's risk management in public safety, and Ethiopia's food security early warning system. The fifth and final chapter looks at how the issue of gender equality is being promoted by public institutions. Since gender 
equality is a cross cutting issue that is equally important in the achievement of all SDGs, its highlight in the Report is imperative. This chapter looks at the national level at how and what type of gender responsive institutions exist, both through legal mechanisms and through the analysis of the institutional principles and associated challenges. In terms of achieving the SDG, the topic focus on achieving gender equality is on education, equal pay, safety and hygiene, and safe transport, all areas where gender inequality is most pronounced as well as areas where significant improvement is possible. The chapter concludes on the issue of the effectiveness of creating gender responsive institutions, an issue often discussed in the context of public institutions.

What makes this Report particularly valuable is in the way it integrates a broad theoretical knowledge and understanding of the topics with the most recent data that inform the state of affairs on a particular topic, and it does so in a way that is easy to follow and comprehend. In other words, the Report retains credibility and rigor without getting too entangled into any academic or research area, thus covering the topics in an easy to understand way.

In some way the Report brings together the diversity of the topic areas covered and offers perspectives on how existing policies or approaches may or may not work to further the SDG 16. Furthermore, it integrates the latest information and data on topics which are often difficult to find, and which have historically not been well covered in some fields of research. One such area is that of anti-corruption, notorious for the lack of reliable and comparable data, where research is still limited when compared to other developmental issues. The Report offers a considerable richness of data sources, summarizing the main trends in the anti-corruption efforts documented while offering specific examples of local or sectoral strategies to enrich the understanding of a topic that can be abstract at times (there are examples of voluntary multi-stakeholder anti-corruption initiatives in different sectors; examples of social accountability initiatives and their effects specified in several countries).

Another notable aspect of the Report is the multidisciplinary approach, its lack of disciplinary bias, thus offering a comprehensive and complete picture of the topic analyzed. Finally, the integration of the public budgeting processes as a tool of implementation of the SDG is thorough, well structured, and appropriate in addressing all the main institutional principles of transparency, inclusive participation, nondiscrimination and anti-corruption. This chapter will be particularly useful for direct application by governments who wish to make their budgets more responsive and responsible.

While the Report is not expected to offer an exhaustive analysis of the SDG 16 institutional principles, the choice of coverage of examples and focus is somewhat guided by the professional background of the individuals contributing to the Report. While this is expected to an extent and it does not make the Report any 
less valuable, it is inevitable that some topics may not be touched upon. For example, when discussing corruption and its definition, as well as anti-corruption measures, the Report does not delve into types of corruption other than distinguishing it by level and or causal models. However, one aspect of corruption is organized crime, where the state and criminal groups are closely tied, and can also involve illicit international activities, such as the arms trade in cases in which the perpetrators are supposed to be enforcing the international laws they are breaking. In these cases, existing anti-corruption measures may not be effective, and the Report may just need to include such areas that are yet to be addressed.

In summary, the World Public Sector Report does an excellent job at presenting the current progress on the institutional dimension of SDG 16 and while it does not provide for a detailed analysis of the global condition, it offers a solid, and reliable foundation for different stakeholders - academic, in local and national government and in NGOs - interested in making progress towards the achievement of the institutional dimensions of SDG 16, and makes for a worthwhile reading for anyone who wishes to have a broad perspective on this SDG. 